\title{
Studying the Curing Conditions of Unsaturated Polyesters from Secondary Polyethylene Terephthalate Alcoholysis Products
}

\author{
Asror B. Juraev, Farhad A. Magrupov, Muzafar G. Alimukhamedov, Ravshan I. Adilov, \\ Muqaddas M. Shokirova, Muqadam G. Ishmukhamedova
}

Tashkent Chemical-Technological Institute, Tashkent, Republic of Uzbekistan

Email: asror_tcti@mail.ru

How to cite this paper: Juraev, A.B., Magrupov, F.A., Alimukhamedov, M.G., Adilov, R.I., Shokirova, M.M. and Ishmukhamedova, M.G. (2020) Studying the Curing Conditions of Unsaturated Polyesters from Secondary Polyethylene Terephthalate Alcoholysis Products. Open Journal of Polymer Chemistry, 10, 77-86. https://doi.org/10.4236/ojpchem.2020.1040 $\underline{05}$

Received: October 24, 2020

Accepted: November 27, 2020

Published: November 30, 2020

Copyright $\odot 2020$ by author(s) and Scientific Research Publishing Inc. This work is licensed under the Creative Commons Attribution International License (CC BY 4.0).

http://creativecommons.org/licenses/by/4.0/

\begin{abstract}
The technological properties of the curing conditions for unsaturated polyesters synthesized on the basis of the alcoholysis products of secondary polyethylene terephthalate and unsaturated polyesters used in the production of fiberglass pipes were studied. It is shown that unsaturated polyesters synthesized on the basis of alcoholysis products can completely replace imported resins of grades 196 and 196A in the production of fiberglass pipes.
\end{abstract}

\section{Keywords}

Secondary Polyethylene Terephthalate, Alcoholysis Product, Unsaturated Polyesters, Grades PN-MA-03, PN-MA-03A, 196 and 196A, Technological and Physical-Mechanical Properties

\section{Introduction}

The disposal of polymer wastes has grown into one of the most urgent problems in environmental protection. This waste cannot be burned, and it must not be buried, because the combustion products of polymer waste further pollute the atmosphere, releasing a large amount of soot and highly toxic combustion products; due to their high resistance to fungi, water and various environments, these products are stored for a long time without decomposing [1] [2].

On the other hand, polymer waste is readily available and inexpensive raw materials for the production of polymer-composite materials [3]-[8].

One of the large-tonnage types of waste, after polyolefins, is polyethylene terephthalate (PET)-containing waste. 
Over the past decade, the global production of polyethylene terephthalate (PET) has increased from 37.5 million tons to 70.0 million tons [9] [10] [11] [12] [13]. Of this amount, 21.5 million tons are used in the production of polymer containers, such as bottles. Hundreds of thousands of tons of various polymers and, in particular, 40 - 45 thousand tons of PET are annually imported to the Republic of Uzbekistan. Of these, about 90\% is recycled into PET forms, which are then shaped into bottles. After using the bottles, they become household polymer waste. Disposal of the generated household polyethylene terephthalate waste is currently relevant.

In recent years, a number of enterprises for the production of fiberglass, sanitary ware, and pipes based on unsaturated polyesters (UPEs) have been organized in the Republic. This has created a demand for this type of polymer material.

Numerous studies have shown the possibility of obtaining UPEs from the alcoholysis products of secondary polyethylene terephthalate (SPET) [14]-[21].

In the work [3], based on the alcoholysis products, we obtained UPE suitable for the production of fiberglass pipes.

This article is devoted to the synthesis and the study of the technological parameters of curing new grades of UPE suitable for the production of fiberglass pipes.

\section{Materials and Methods}

The used raw materials were recycled PET, namely, that formerly used as bottles for drinks, which crushed in a crusher to a size of $0.5 \times 0.5 \mathrm{sm}$, with melting point of $240^{\circ} \mathrm{C}-250^{\circ} \mathrm{C}$. Diethylene glycol produced in Russia was first purified by vacuum distillation over a temperature range of $128^{\circ} \mathrm{C}-135^{\circ} \mathrm{C}$ and with a residual pressure of $0.90-0.97 \mathrm{kgf} / \mathrm{sm}^{2}$. The distilled product had a refractive index $\mathrm{n}_{\mathrm{d}}=1.4472$ and $\rho=1.1191 \mathrm{~g} / \mathrm{cm}^{3}$. Propylene glycol had a refractive index $\mathrm{n}_{\mathrm{d}}$ $=1.4326$ and $\rho=1.036 \mathrm{~g} / \mathrm{sm}^{3}$. Maleic anhydrideb was used according to SS 11153-75. Phthalic anhydride was used according to SS 5869-77. Zinc acetate was used according to SS 5823-78.

The synthesis of UPE was carried out according to the method described in [3].

As the main alcoholic component, we used the products of alcoholysis of SPET obtained with a ratio of SPET: diethyleneglycol $(D E G)=1: 2$ mole el. unit/mole, for 6 hours according to the method described in [4], and the UPE itself was synthesized according to the method described in [3].

The suitability of UPEs for processing was assessed according to the following technological parameters adopted in the production of pipes: visual appearance based on the conditional viscosity determined by a Brookfield device at $23^{\circ} \mathrm{C}$, gelatinization time according to SS 22181-91, maximum exothermic temperature during the curing process and the self-heating duration according to SS 21970-70, and mass fraction of non-volatile substances according to SS 17537-72. Polyester resins of grades 196 and 196A (made in China) were chosen for comparisons. 


\section{Discussion of the Results}

UPEs of grades 196 and 196A according to technological normative documentation (TND) must correspond to the physicochemical and technological indicators given in Table 1 .

In the enterprises of Uzbekistan, in particular JV Ltd. "MEGA MEBIKO”, resin grade 196A is used as the protective layer, and resin grade 196 is used as the inner layer of pipes.

Initially, in order to determine the structure of UPEs of grades 196 and 196A, their IR spectra were studied. Therefore, the polyesters were washed to remove styrene and traces of monomers, and then their IR spectra were recorded (Figure 1(a) and Figure 1(b)).

The IR spectra of UPE grades 196A (a) and 196 (b) have similar pass bands for the aromatic rings at 3077,1600 , and $1580 \mathrm{~cm}^{-1}$, and the pass band at $1074 \mathrm{~cm}^{-1}$ indicates the type of 1.4 substitution in the aromatic ring. This indicates that the composition of UPE contains phthalic anhydride residues. In addition, the spectra have transmission bands at 1730,1726 , and $1156 \mathrm{~cm}^{-1}$, which are characteristic of the ester groups -CO-O- and at $1645,1643 \mathrm{~cm}^{-1}-\mathrm{C}=\mathrm{C}-$ bonds. In this case, UPEs contain a mixture of cis- and trans $\mathrm{C}=\mathrm{C}$ bonds. The transmission bands at 2956, 2928, 1453, $1447 \mathrm{~cm}^{-1}$ indicate the presence of methyl groups in the UPE; the pass band at $2880,2875 \mathrm{~cm}^{-1}$ indicates the presence of methylene groups in UPEs.

The pass bands at $1453,746 \mathrm{~cm}^{-1}$ are characteristic of methylene groups, and the number of methylene groups in the aliphatic chain is less than four [22] [23] [24].

The presence of all the above pass bands in the IR-spectra of both brands of UPEs (insignificant differences only in the intensities of some pass bands) indicates the identity of the structure of both brands of UPEs. In all probability, both grades (196 and 196A) differ only in the content of the active solvent of styrene (respectively, in the dry residue).

Therefore, it can be assumed that the used unsaturated polyesters of grades 196 and 196A produced in China have the same structure and are synthesized

Table 1. Technological properties of UPE grades 196 and 196A.

\begin{tabular}{cccc}
\hline № & Indicators & Grade 196 & Grade 196A \\
\hline 1 & Density, $\mathrm{kg} / \mathrm{m}^{3}$ & 1145 & 1120 \\
2 & Viscosity, Brookfield, $23^{\circ} \mathrm{C}, \mathrm{mPa} \cdot \mathrm{s}$ & $500-1000$ & $250-500$ \\
3 & Acid number, mgKOH/g & $17-25$ & $17-23$ \\
4 & Solids content, $\%$ & $68-75$ & $63-68$ \\
5 & Gelatinization time, min & $6-18$ & $9-18$ \\
6 & Maximum heating temperature, ${ }^{\circ} \mathrm{C}$ & $\geq 120$ & $\geq 130$ \\
7 & Self-heating duration, min & $15-25$ & $20-30$ \\
8 & Bending strength, $\mathrm{MPa}$ & $\geq 100$ & $\geq 100$ \\
\hline
\end{tabular}




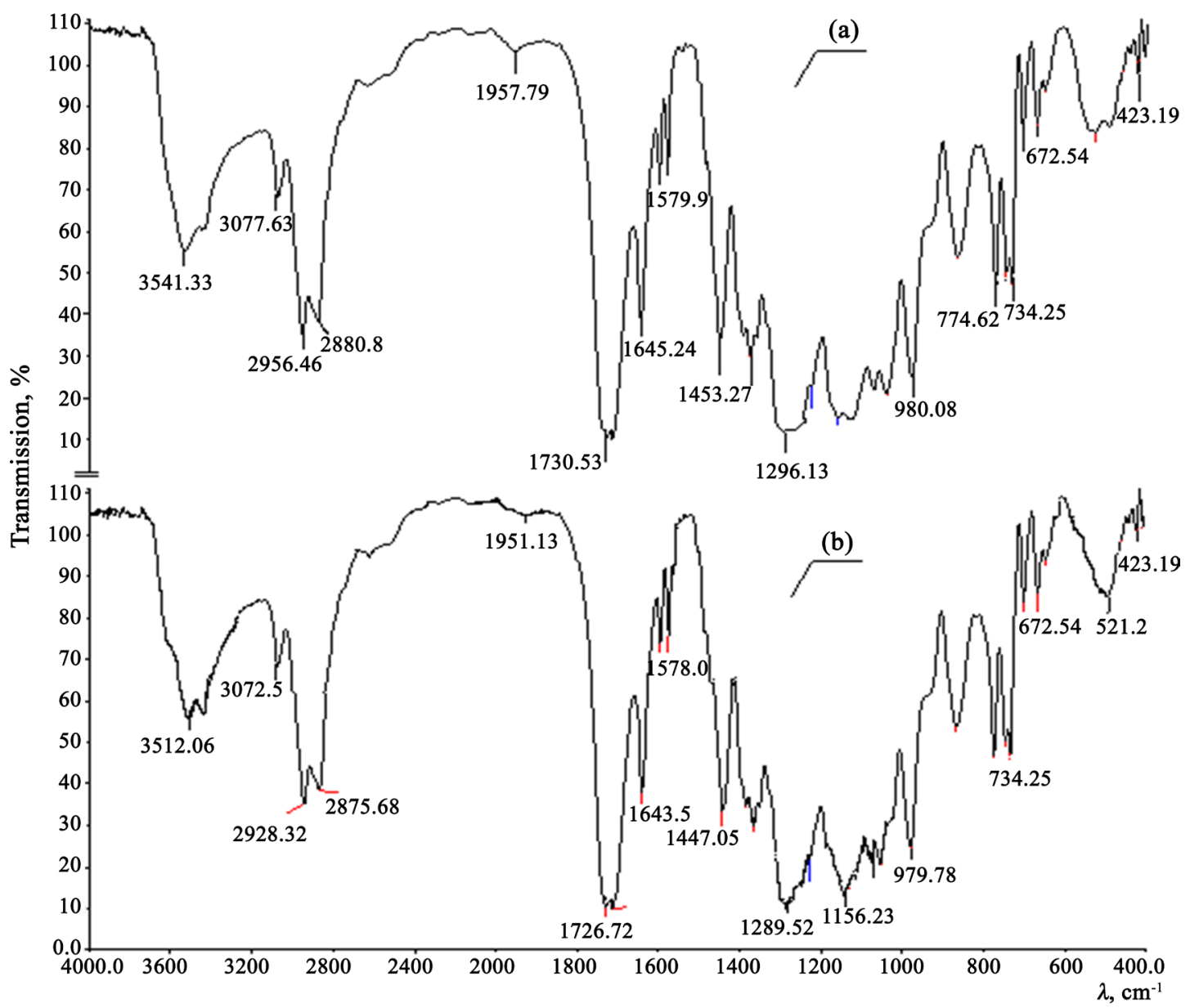

Figure 1. IR-spectra of unsaturated polyester resins of grades 196A (a) and 196 (b).

from maleic and phthalic anhydrides, ethylene and propylene glycols.

After numerous studies, we selected the following synthesis formulation (in moles) of UPE: alcoholysis product of SPET (SPET:DEG = 1:2) - 1.0; DEG - 2.5; propylene glycol (PG) - 3.0; phthalic anhydride - 1.7; and maleic anhydride - 4.5 .

After the completion of the synthesis of UPE according to the above formulation and the method of work [3], the reaction mass was cooled to $90^{\circ} \mathrm{C}-80^{\circ} \mathrm{C}$ and by adding 30\% styrene an analog of resin grade 196 and 34\% of styrene an analog of resin 196A were obtained. An analogue of resin grade 196 (Liner) was designated as grade PN-MA-03A, and an analogue of grade 196A (Body) as grade PN-MA-03. A comparative table of the physicochemical properties and mechanical characteristics of the synthesized UPE and their analogs determined in laboratory conditions are given in Table 2. In this case, a system of methyl ethyl ketone peroxide (MEKP): cobalt naphthenate $(\mathrm{CN})$ in a ratio of 1:0.5 mass f. was used as the hardener according to the mass of UPE.

From the data in Table 2, it can be seen that the UPE synthesized by us in terms of such indicators as the duration of self-heating, the maximum exothermic temperature, impact strength and bending strength correspond and meet the standards for resins of grades 196 and 196A. 
This result gave us the opportunity to obtain pilot run of UPE at the facility of JV UZKABEL JSC, which later became the objects of further research. Some properties of the obtained experimental batches of UPE are shown in Table 3.

It is known that the process of curing unsaturated polyesters is accompanied by intense heat release, the rate and time of which determine the conditions for processing these oligomers.

The speed and time of curing is greatly influenced by the concentration of the accelerator. Therefore, in the studies, the amount of the accelerator varied from 0.3 to 0.5 mass $n$.

From the data in Figure 2 and Figure 3, it can be seen that with an increase in the amount of accelerator from 0.3 to 0.5 mass units for UPE grade PN-MA-03 (curve 1), a decrease in the gelatinization time from 13.5 to $12 \mathrm{~min}$., The duration of self-heating changed from 27.5 to $25 \mathrm{~min}$. and an increase in the exothermic temperature occurred from $121^{\circ} \mathrm{C}$ to $135^{\circ} \mathrm{C}$. In the case of UPE grade PN-MA-03A, a decrease in the gelation time from 16 to 14.5 min. occurred, and the duration of self-heating changed from 29 to 23 minutes along with an increase in the exothermic temperature from $117^{\circ} \mathrm{C}$ to $121^{\circ} \mathrm{C}$ (curve 2). A comparison of the above data shows that an increase in the amount of cobalt naphthenate, although it leads to an increase in the rates of their curing in both brands of the analyzed UPE, this effect is different.

An analysis shows that an increase in the amount of accelerator accelerates the curing process of UPE grade PN-MA-03A to a greater extent than the UPE

Table 2. Comparative table of physicochemical and mechanical characteristics of the synthesized UPE and UPE grades 196 and 196A.

\begin{tabular}{|c|c|c|c|c|c|}
\hline № & Indicators & $\begin{array}{l}\text { UPE grade } \\
\text { 196, "Liner" }\end{array}$ & $\begin{array}{l}\text { UPE grade } \\
\text { "PN-MA-03A" }\end{array}$ & $\begin{array}{l}\text { UPE grade } \\
\text { 196A, "Body" }\end{array}$ & $\begin{array}{l}\text { UPE grade } \\
\text { "PN-MA-03" }\end{array}$ \\
\hline 1 & Density, $\mathrm{kg} / \mathrm{m}^{3}$ & 1114 & 1122 & 1100 & 1118 \\
\hline 2 & $\begin{array}{l}\text { Viscosity, on the Brookfield, } \\
\qquad 23^{\circ} \mathrm{C}, \mathrm{mPa} \cdot \mathrm{s}\end{array}$ & 898 & 850 & 420 & 448 \\
\hline 3 & Gelatinization time, min & 13 & 13.5 & 14 & 13 \\
\hline 4 & $\begin{array}{l}\text { Maximum heating } \\
\text { temperature, }{ }^{\circ} \mathrm{C}\end{array}$ & 128 & 121 & 136 & 138 \\
\hline 5 & Self-heating duration, $\min$ & 22 & 24.5 & 23.5 & 26.5 \\
\hline 6 & Solids content, $\%$ & 70.2 & 71.5 & 66.0 & 67.0 \\
\hline 7 & Impact strength, $\mathrm{kJ} / \mathrm{m}^{2}$ & 4.95 & 5.02 & 4.5 & 4.5 \\
\hline 8 & Static bending strength, $\mathrm{MPa}$ & 99.5 & 103.2 & 98.0 & 102 \\
\hline
\end{tabular}

Table 3. Physicochemical properties of a pilot run of UPE.

\begin{tabular}{ccc}
\hline Indicators & PN-MA-03A & PN-MA-03 \\
\hline Density, $\mathrm{kg} / \mathrm{m}^{3}$ & 1126 & 1120 \\
Viscosity, Brookfield, $23^{\circ} \mathrm{C}, \mathrm{mPa} \cdot \mathrm{s}$ & 920 & 465 \\
Solids content, \% & 69,5 & 65,5
\end{tabular}




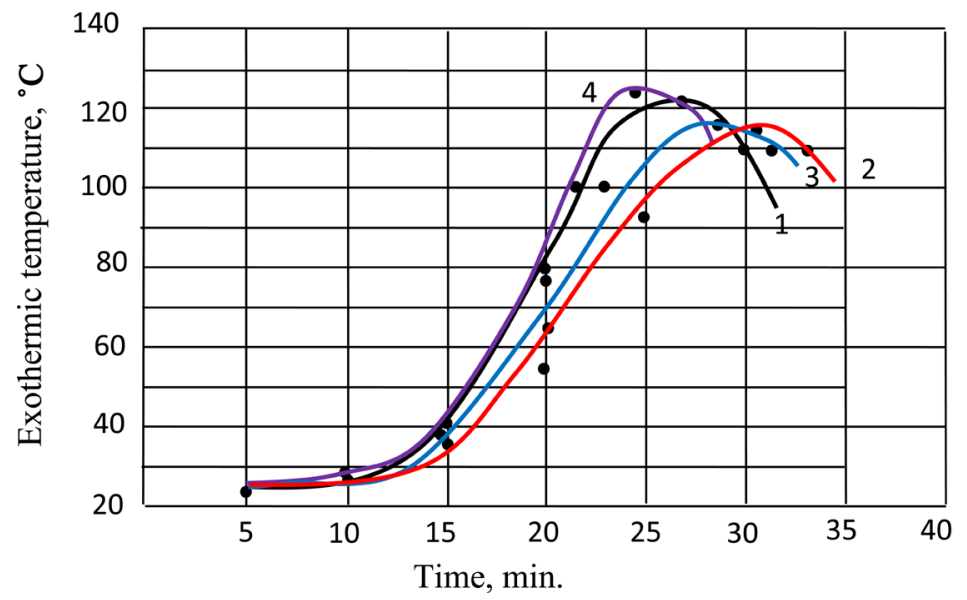

Figure 2. Exothermic curve of the curing of polyesters with the accelerator content of cobalt naphthenate of 0.3 mass units. 1-PN-MA--03; 2-PN-MA-03A; 3-196A; 4-196.

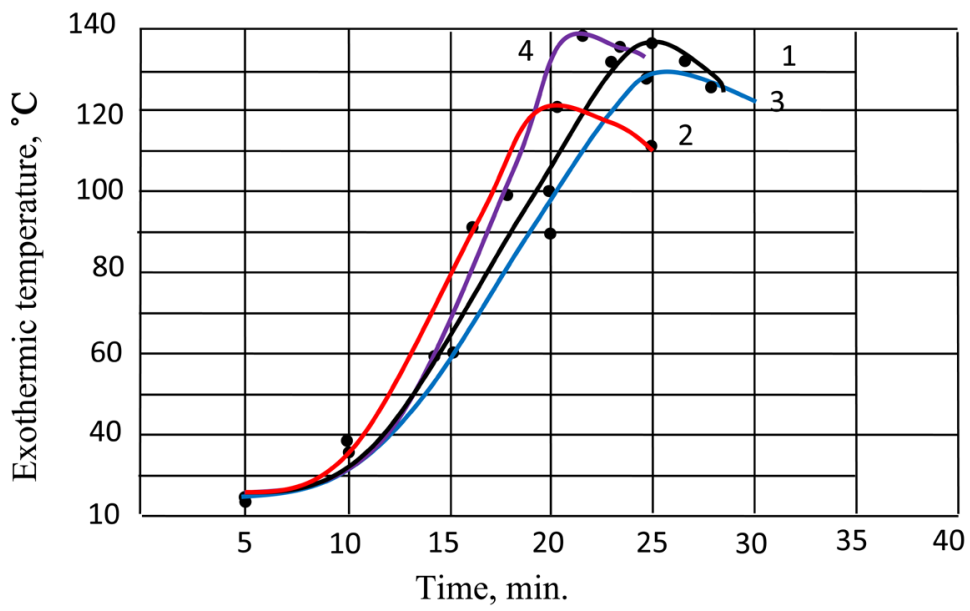

Figure 3. Exothermic curve of the curing of polyesters with the accelerator content of cobalt naphthenate of 0.5 mass units. 1-PN-MA-03; 2-PN-MA-03A; 3-196A; 4-196.

grade PN-MA-03A to a greater extent than the UPE grade PN-MA-03A. .

It should be noted that a similar dependence of the curing rates depending on the amount of cobalt naphthenate is observed in industrially used UPE grades 196A and 196 (Figure 2 and Figure 3, curves 3 and 4). This is expected, since UPE grades PN-MA-03 and 196A contain more of the active solvent-styrene, as a result of copolymerization with unsaturated polyesters and acceleration of their curing processes occurs.

IR spectroscopic studies of the structure and curing process of UPE of grade PN-MA-03 showed that UPE obtained from the alcoholysis products of SPET also obeys the general laws of the curing processes of UPE.

The IR-spectra of styrene (Figure 4, curve 1) show the passbands of the aromatic ring at $3059,1600,1575,908,775$, and $697 \mathrm{~cm}^{-1}$, vinyl groups at 3027 , 1819,1630 , and $1413 \mathrm{~cm}^{-1}$. The monosubstituted aromatic ring gives peaks of transmission at 775, $697 \mathrm{~cm}^{-1}$ [22] [23] [24].

UPE grade PN-MA-03 exhibits transmission bands (Figure 4, curve 2) at 


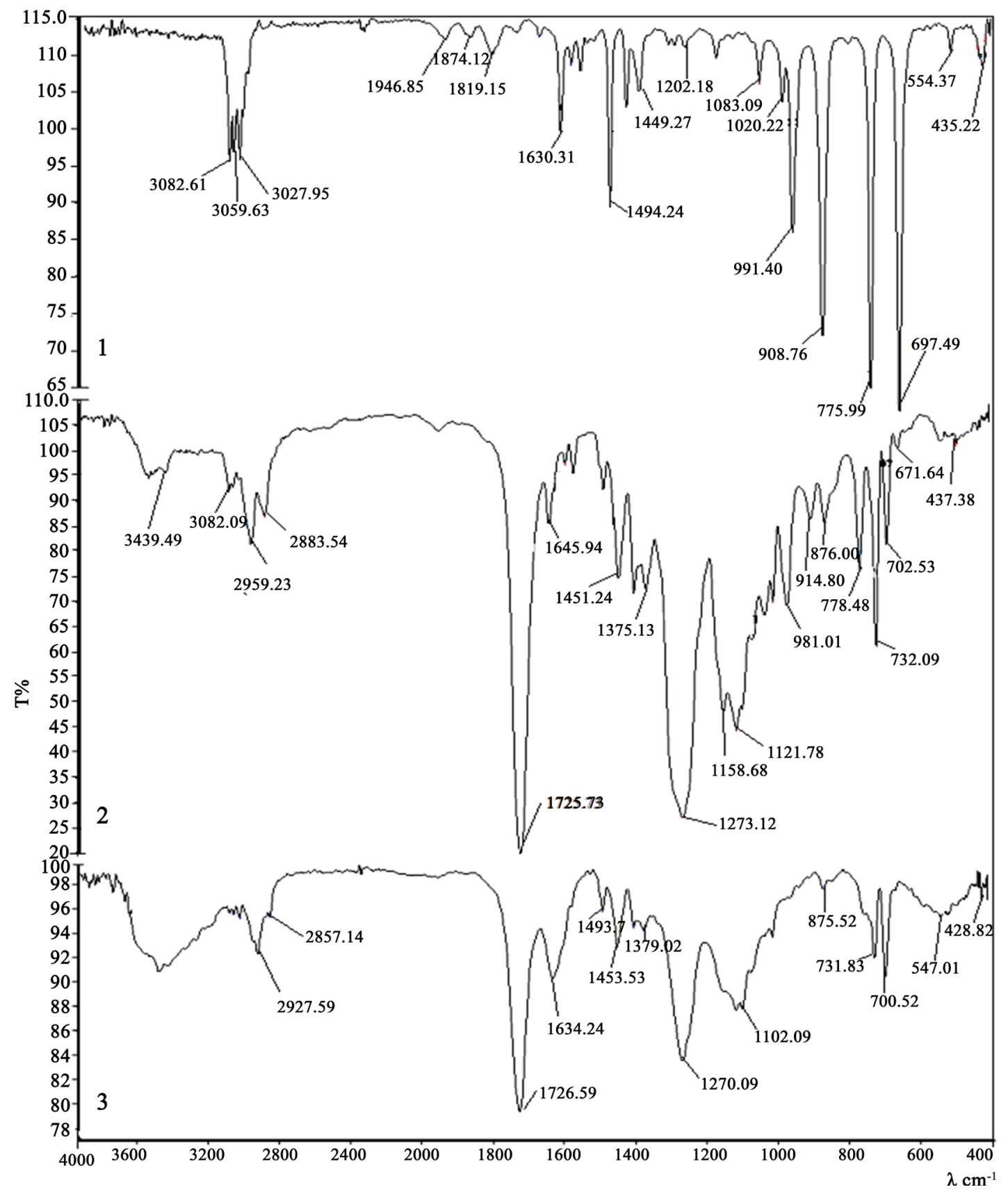

Figure 4. IR spectra of styrene (1), 65.5\% solution of PN-MA-03 grade in styrene (2) and cured grade PN-MA-03 (3).

3082, 1600, 1578, 914, and $876 \mathrm{~cm}^{-1}$ (1,4-substituted aromatic ring); at 1725 , 1158 , and $1121 \mathrm{~cm}^{-1}$ (ester group, at 1645,980 , and $732 \mathrm{~cm}^{-1}$ (cis-, trans-allyl groups, 2959, 2883,1451, $778 \mathrm{~cm}^{-1}$ (methylene groups), styrene at 3082, 1494, and $671 \mathrm{~cm}^{-1}$ (aromatic ring, $1940 \mathrm{~cm}^{-1}$ (overtone). Vinyl band pass bands at 3027,1630 , and $991 \mathrm{~cm}^{-1}$ that overlap with the aromatic ring pass bands and appear at 1645 and $919 \mathrm{~cm}^{-1}$.

After curing in the IR-spectra of the cross-linked polymer (Figure 4, spectrum 3 ), the pass bands of vinyl groups (overtone $-\mathrm{CH}=\mathrm{CH}_{2}$ ) disappear at 1819 and 
Table 4. Physical and mechanical properties of cured UPE resins.

\begin{tabular}{|c|c|c|c|c|c|c|c|c|c|}
\hline \multirow{4}{*}{ № } & \multirow{4}{*}{ Indicators } & \multicolumn{8}{|c|}{ Unsaturated polyester } \\
\hline & & \multicolumn{2}{|c|}{ PN-MA-03 } & \multicolumn{2}{|c|}{ Resin “196A” } & \multicolumn{2}{|c|}{ PN-MA-03A } & \multicolumn{2}{|c|}{ Resin “196” } \\
\hline & & \multicolumn{8}{|c|}{ Accelerator concentration, mass. part } \\
\hline & & 0.3 & 0.5 & 0.3 & 0.5 & 0.3 & 0.5 & 0.3 & 0.5 \\
\hline 1 & Impact strength, $\mathrm{kJ} / \mathrm{cm}^{2}$ & 4.3 & 5.0 & 4.0 & 4.6 & 4.2 & 4.7 & 4.3 & 5.1 \\
\hline 2 & Static bending strength, $\mathrm{MPa}$ & 95.2 & 106.6 & 94.2 & 100.5 & 97.2 & 104.5 & 97.9 & 101.5 \\
\hline 3 & Vicat heat resistance, ${ }^{\circ} \mathrm{C}$ & 172 & 178 & 161 & 165 & 168 & 170 & 150 & 153 \\
\hline 4 & Gel fraction yield, $\%$ & 93.5 & 94.5 & 92.5 & 93.2 & 94 & 94.8 & 89.5 & 92.2 \\
\hline
\end{tabular}
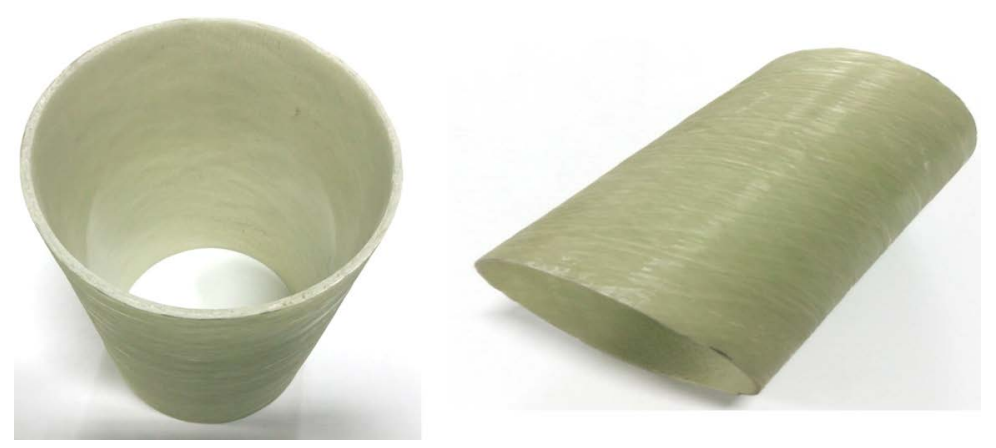

Figure 5. A sample of a fiberglass pipe obtained from unsaturated polyesters of the PN-MA-03 and PN-MA-03A grades.

$1663 \mathrm{~cm}^{-1}$, trans allyl groups at $1645,980 \mathrm{~cm}^{-1}$, and a sharp decrease in pass bands at $732-731 \mathrm{~cm}^{-1}$ related to cis-allyl bonds.

The observed evidence suggests that the curing of unsaturated polyester first proceeds due to the polymerization of vinyl (in styrene) and trans-allyl groups (in UPE), and then, after the consumption of trans allyl groups, due to the polymerization of cis-allyl groups [25] [26].

In this case, styrene homopolymerization also occurs with the formation of oligomers, which are involved in the crosslinking of UPE [26]. Table 4 shows the effect of the accelerator system on the physical and mechanical properties of the cured UPE resins.

According to the accepted standard in the joint venture "MEGA MEBIKO", fiberglass pipes were manufactured and withstood the hydrostatic pressure of water equal to $25 \mathrm{~atm}$. A sample is shown in Figure 5.

\section{Conclusion}

Thus, comparative studies of the curing conditions of synthesized UPE resins of grades PN-MA-03 and PN-MA-03A with industrial analogues of grades 196 and 196A have been carried out. The effect of the amount of accelerators on the technological parameters of the curing of these resins has been shown. At the same time, the physical and mechanical properties of the synthesized polyesters of grades PN-MA-03 and PN-MA-03A have been studied and it has been found 
that the synthesized polyesters fully meet the requirements for resins used in the production of fiberglass pipes.

\section{Conflicts of Interest}

The authors declare no conflicts of interest regarding the publication of this paper.

\section{References}

[1] https://eko-a.ru/utilizatsiya_otkhodov/otkhody_polimernykh_materialov

[2] https://e-plastic.ru/specialistam/vtorichnaya-pererabotka/utilizaciya-polimernykhmaterialov-ispolzuemykh-v-stroitelstve/

[3] Juraev, A.B., Adilov, R.I., Nizomov, T.A., Alimuxamedov, M.G. and Magrupov, F.A. (2014) Synthesis and Research of Unsaturated Polyethers on the Basis of Secondry Polyethyline Terephthalate. Kautschuk Gummi Kunststoffe, 41-44.

[4] Juraev, A.B., Alimuxamedov, M.G., Magrupov, F.A., Adilov, R.I. and Nizomov, T.A. (2017) Synthesis and Research of Tube-Purposed Unsaturated Polyethers of Alcoholysis of Secondary Polyethylene Terephthalate. Kautschuk Gummi Kunststoffe, 70-74.

[5] Znang, Y., Zhang, H., Yu, Y., Guo, W. and Wu, C. (2009) Recycled Poly(Ethylene Terephthalate)/Linear Low-Density Polyethylene Blends Througs Physical Processing. Journal of Applied Polymer Science, 114, 1187-1194. https://doi.org/10.1002/app.30030

[6] Raheem, A.B. and Uyigue, L. (2010) The Conversion of Post-Consumer Polyethylene Terephthalate (PET) into a Thermosetting Polyester Resin. Archives of Applied Science Research, 2, 240-254.

[7] Duque-Ingunza, I., Lopez-Forseca, R., de Rivas, B. and Gutierrez-Ortiz, J.I. (2013) Synthesis of Unsaturated Polyester Resin from Glycolysed Postconsumer PET Wastes. Journal of Material Cycles and Waste Management, 15, 256-263. https://doi.org/10.1007/s10163-013-0117-x

[8] Achilias S.D., Tsintzou G.P., Nikolaidis A.K., Bikiaris D.N. and Karayannidis G.P. (2011) Aminolytic Depolymerization of Poly(Ethylene Terephthalate) Waste in a Microwane Reactor. Polymer International, 60, 500-506. https://doi.org/10.1002/pi.2976

[9] Swift, D. (2014) In a Year of Adversity, Cold Europe be Flooded with PET/PCL, 15th GEPET, Dubrovnik, May 2014. https://www.polymerbranch.com/magazine/magdocs/view/194.html

[10] https:.www.petnology.com/competence-online/news/visiongate-rpet-market-report -2020-2030.html

[11] https://flexpet.ru/conference-pet-2016

[12] https:sustainablebrands.com/read/waste-not/the-many-challenges-of-plastic-recycl ing

[13] http:.www.bafu.admin.ch/dokumentation/medieninformation/00962/index.html?la $\underline{n g}=$ fr\&msg-id $=50084$

[14] Katoch, S. (2013) Kinetics Study of Unsaturated Polyester synthesized from waste PET. Asian Journal of Advanced Basis Sciences, 1, 87-92.

http://www.eresearchco.com/ajabs/12_sunain_katoch.pdf

[15] Juraev, A.B., Alimuhamedov, M.G. and Magrupov, F.A. (2020) Fiberglass Pipes from the Unsaturated Polyether on the Basis of Alcoholysis Products of Secondary Polyethylene Terephthalate. International Conference Scientific Researches for De- 
velopment Future, New York, 28 March 2020.

[16] Juraev, A.B., Alimukhamedov, M.G., Magrupov, F.A., Adilov, R.I. (2016) Study of the Effect of the Structure of Alcoholysis Products of Secondary Polyethylene Terephthalate on the Properties of Unsaturated Polyesters Based on Them. Journals the chemical chemistry of Uzbekistan, 65-70.

[17] Farahat, M.S., Abdel-Azim, A.-A.A. and Abdel-Raow, M.E. (2000) Modified Unsaturated Polyester Resins Synthesized from Poly(Ethylene Terephthalate) Waste 1. Synthesis and Curing Characteristics. Macromolecular Materials and Engineering, 283, 1-6. https://doi.org/10.1002/1439-2054(20001101)283:1<1::AID-MAME1>3.0.CO;2-V

[18] Pimpan, V., Sirisook, R. and Chuayjuljit, S. (2003) Synthesis of Unsaturated Polyester Resin from Postconsumer PET Bottles: Effect of Type of Glycol on Characteristics of Unsaturated Polyester Resin. Journal of Applied Polymer Science, 88, 788-792. https://doi.org/10.1002/app.11567

[19] Suh, D.J., Park, O.O. and Yoon, K.H. (2000) The Properties of Unsaturated Polyester Based on the Glycolyzed Poly(Ethylene Terephthalate) with Various Glycol Compositions. Polymer, 41, 461-466. https://doi.org/10.1016/S0032-3861(99)00168-8

[20] Kim, J, Jeong, D., Son, C., Lee, Y. Kim, E. and Moon, I. (2007) Synthesis and AApplications of Unsaturated Polyester Resins Based on PET Waste. Korean Journal of Chemical Engineering, 24, 1076-1083. https://doi.org/10.1007/s11814-007-0124-5

[21] Tahvildari, K., Mozafari, S. and Tarinsun, N. (2010) Chemical Recycling of Poly Ethylene Terephthalat to obtain Unsturated Polyester Resins. Journal of Applied Chemical Research, 12, 59-68.

[22] Kazitsyna, L.A. and Kupletskaya, N.B. (1971) Application of UV, IR, NMR-Spectroscopy in Organic Chemistry.

[23] Nakanishi, K. (1965) Infrared Spectra and Structure of Organic Compounds/Translated from English.

[24] Mistry, B.D. (2009) A Handbook of Spectroscopic Data Chemistry (UV, IR, PMR, ${ }^{13} \mathrm{CNMR}$ and Mass Spectroscopy). Oxford Book Co. Jaipur.

[25] Ulrich Pot. (2009) Polyesters and Alkyd Resins/Translation from German.

[26] Lebedev, I.K. and Naumets, V.N. (2015) Corrosion-Resistant Pipes and Containers Made of Fiberglass: Materials, Properties, Technologies. 